First publ. in: Federal Reserve Bank of St. Louis Review 91 (2009), 2, pp. 95-106

\title{
Firm Volatility and Credit: A Macroeconomic Analysis
}

Leo Kaas

\begin{abstract}
This paper examines a tractable real business cycle model with idiosyncratic productivity shocks and binding credit constraints on entrepreneurs. The model shows how firm volatility increases in combination with credit market development. It further generates the observed comovement of credit and firm volatility with output at business cycle frequencies in response to aggregate productivity shocks. (JEL E32, E44, O16)
\end{abstract}

Federal Reserve Bank of St Louis Review, March/April 2009, 91(2), pp. 95-106.

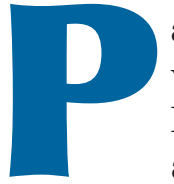

arallel to the decline in macroeconomic volatility over the past decades (see Blanchard and Simon, 2001, and Stock and Watson, 2002), there is some evidence that volatility at the firm level has increased during the same period. For the United States, such evidence is available for idiosyncratic stock returns (Campbell et al., 2001), as well as for employment, sales, and investment. Comin and Mulani (2004) and Comin and Philippon (2005) document similar results for other countries. ${ }^{1}$

There are different explanations for an increase in firm volatility. One is that deregulation and intensified global competition force firms to adjust prices and business strategies faster. Another is that financial development leads to more risktaking by entrepreneurs or facilitates leverage, which both could potentially drive up firm volatility. Indeed, Comin and Philippon (2005) find some support for both hypotheses. They also show that the increase in firm volatility is driven neither by the growing share of small firms in the sample nor

1 Davis et al. (2006) demonstrate, however, that firm-level employment volatility has increased only for publicly traded firms and not for privately held firms. changes in firm ownership, including merger and acquisition activities.

This paper puts the link between financial development and firm volatility in a macroeconomic perspective. To this end, I develop a tractable real business cycle model with idiosyncratic productivity shocks and collateral-based borrowing constraints. Productive entrepreneurs borrow up to the value of their collateral. Because their capital return exceeds the capital cost, the leveraged return on equity exceeds the equity return of less-productive entrepreneurs. An increase in credit market development relaxes borrowing constraint and increases leverage, and thereby also the spread between internal rates of return across firms. As a result, firm growth rates become more volatile.

Another implication of my model is that both credit market development and firm volatility respond positively to an aggregate productivity shock. Higher productivity raises the value of pledgeable assets, thus softening credit constraints and leverage. Hence, both the volume of firm credit and firm-level volatility are procyclical. In the following section, I demonstrate that such

Leo Kaas is a professor of economics at the University of Konstanz and was a visiting scholar at the Federal Reserve Bank of St. Louis when this paper was written. The author thanks Costas Azariadis and Carlos Garriga for helpful comments and the German Research Foundation for financial support (grant No. KA 1519/3). 


\section{Figure 1}

\section{Business Credit (Share of GDP) and Firm Volatility (Annual U.S. Data 1955-2000)}

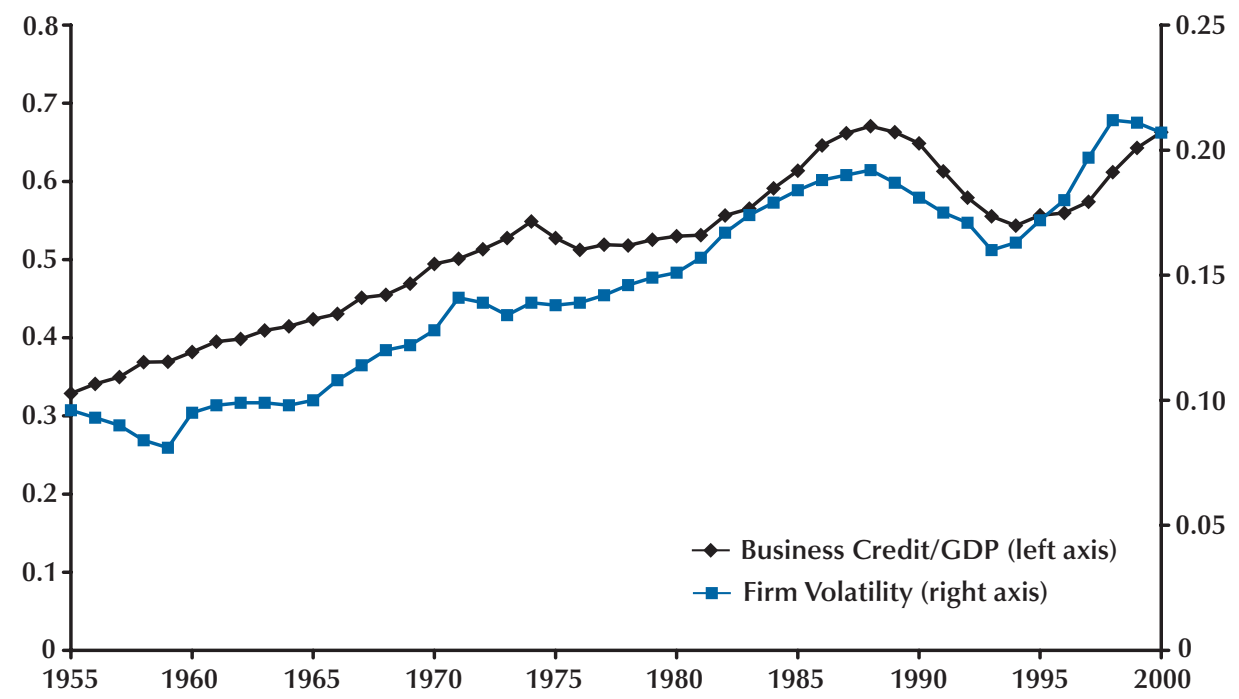

procyclicality is indeed observable in postwar U.S. data. In the quantitative section, I match the model to the U.S. business cycle and show that it replicates reasonably well the comovements among the three key variables of output, credit, and firm volatility. However, the amplification of firm volatility is twice as large as in the data, and its cross-correlations with output and credit are somewhat too low. The model can also be used to investigate the effects of a financial crisis; in particular, a severe crisis where collateral value drops temporarily by 20 percent features a decline of gross domestic product (GDP) below trend by 3.5 percent.

By adopting collateral-based borrowing constraints in combination with logarithmic utility and Cobb-Douglas production technologies, my model is essentially a variation of the approach of Kiyotaki (1998) and Kiyotaki and Moore (2008), who also develop tractable business cycle models with binding credit constraints. Other theoretical contributions on idiosyncratic production risk and finance constraints in dynamic equilibrium models are those of Hopenhayn and Vereshchagina (2003) and Meh and Quadrini (2006). But while they examine risk-taking in incomplete-market environments, the effect of borrowing constraints on firm leverage is the driving force of this paper. Further, the model of this paper has closed-form solutions, which make its basic mechanics particularly clear.

\section{THE EVIDENCE}

For the purpose of this paper, the appropriate measure of credit market development is the share of business credit in GDP, where "business credit" includes all credit market debt owed by nonfinancial firms, including corporations and noncorporations. ${ }^{2}$ Figure 1 illustrates the substantial financial deepening during the period 1955 to 2000; as a share of GDP, business credit roughly doubled. Real business credit actually increased by a factor of 8.9. ${ }^{3}$

\footnotetext{
2 See Board of Governors of the Federal Reserve (2008).

3 Real business credit is defined as business credit divided by the GDP deflator. Over the same horizon, by comparison, real household debt increased by a factor of 9.5 , real government debt by a factor of 4.9, and real credit market debt of the financial sector by a factor of 99.5.
} 
Figure 2

\section{Detrended Real Business Credit and Firm Volatility (Annual U.S. Data 1955-2000)}

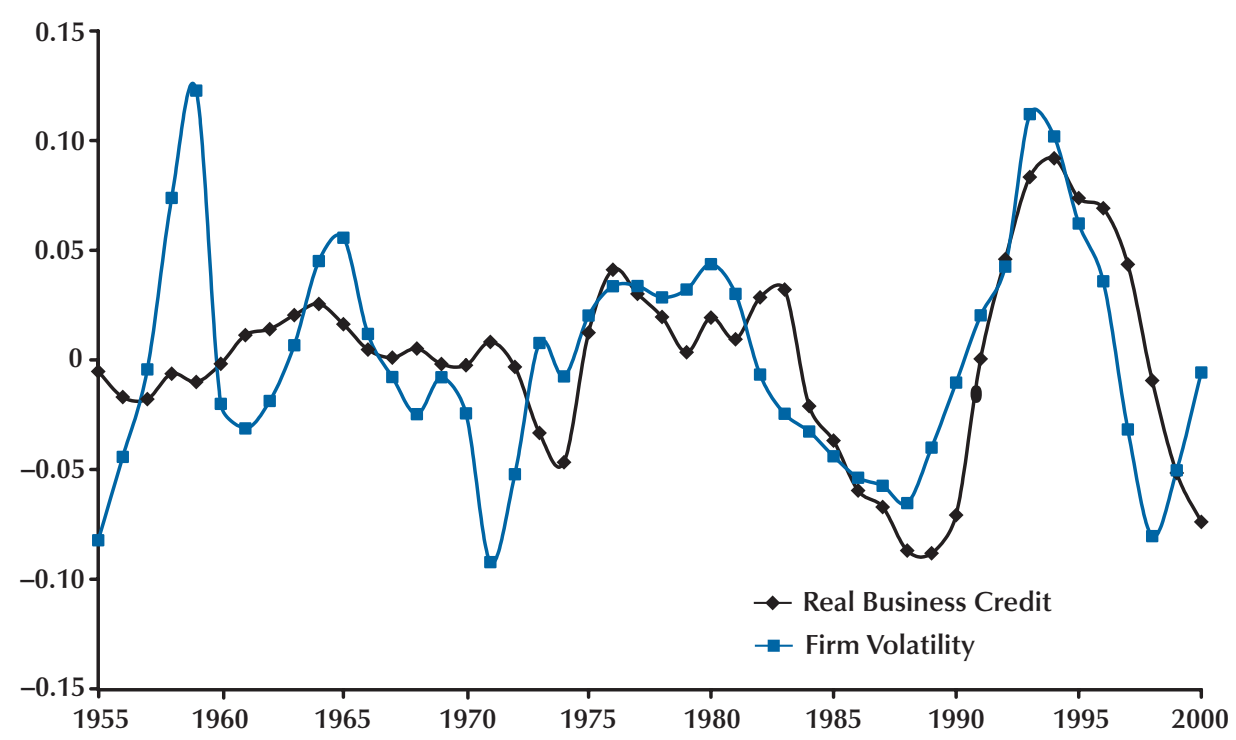

NOTE: Both variables are reported in logs as deviations from a Hodrick-Prescott trend with smoothing parameter 100.

Figure 1 also shows the increase in firm volatility during the same period. I use the "median sales volatility” reported in Comin and Philippon (2005, table 1) as a volatility measure. Specifically, Comin and Philippon calculate a rolling standard deviation (SD) of sales growth for nearly every firm in the Compustat database; the median of the cross section then measures firm volatility at every point in time. It becomes evident from the figure that firm volatility also doubled between 1955 and 2000. Of note, firm volatility is quite dispersed in the cross section. For example, in the 1990s, sales growth volatility was below 0.1 for 25 percent of firms and above 0.3 for another 25 percent of firms (see Figure 2 in Comin and Philippon, 2005).

Figure 1 further suggests that business credit and firm volatility are positively correlated at the business cycle frequency. To see this more clearly, note that Figure 2 shows the detrended time series of real business credit and of firm volatility, where the trend is a Hodrick-Prescott (H-P) filter with $\lambda=100$ and the cyclical components are reported as log deviations from trend. Particularly since

\section{Table 1}

\section{Descriptive Statistics (Annual U.S. Data 1955-2000)}

\begin{tabular}{lccc} 
& Output & Credit & Volatility \\
\hline Standard deviation & 0.021 & 0.042 & 0.050 \\
Annual autocorrelation & 0.546 & 0.826 & 0.675 \\
$\begin{array}{l}\text { Correlation matrix } \\
\quad \text { Output }\end{array}$ & 1 & 0.460 & 0.257 \\
Credit & - & 1 & 0.567 \\
$\quad$ Volatility & - & - & 1
\end{tabular}

NOTE: All variables are reported in logs as deviations from an $\mathrm{H}-\mathrm{P}$ trend with smoothing parameter 100.

the 1970s, the two cycles are closely synchronized and the percentage deviations from trend are similar in magnitude.

Table 1 summarizes the detrended data of output, real business credit, and firm volatility. Both firm volatility and credit have higher variance than output, and they are positively corre- 
lated with contemporaneous output, where the correlation between credit and output is stronger than the one between volatility and output. The correlation coefficient between credit and volatility increases from 0.567 to 0.775 when the period is restricted to the years 1975 to 2000 .

\section{THE MODEL}

Consider a one-sector growth model with infinitely lived entrepreneurs and workers in which either group is a continuum of mass one. All agents derive logarithmic utility from consumption and discount future utility with the factor $\beta<1$. All workers supply one unit of labor inelastically. Entrepreneurs do not supply labor; they employ workers and capital to produce output with a Cobb-Douglas technology, which is subject to idiosyncratic productivity shocks. Specifically, entrepreneur $i$ in period $t$ uses capital $K_{t}^{i}$ and labor $L_{t}^{i}$ to produce output $Y_{t}^{i}=A_{t}^{i}\left(K_{t}^{i}\right)^{\alpha}\left(L_{t}^{i}\right)^{1-\alpha}$, where the entrepreneur's productivity attains the high level $A_{t}^{i}=A_{t}$ (productive state) with probability $\pi$ and the lower level $A_{t}^{i}=B<A$ (unproductive state) otherwise. These productivity realizations are independent across time and across entrepreneurs. Thus, a fraction $\pi$ of entrepreneurs is productive in every period. The assumption that productivity states are independent of history simplifies the exposition but can easily be generalized to allow for autocorrelated productivity states. The only complication is that the model must then be augmented by another state variable, which is the share of wealth in the hands of productive entrepreneurs.

Factor productivity at the technology frontier $A_{t}$ is subject to aggregate productivity shocks. In particular, $\ln A_{t}$ follows an AR(1) process with coefficient $\rho<1$, mean $\ln \bar{A}$, and normally distributed shocks with SD $\sigma$. The assumption that only the frontier $A$ fluctuates while the inferior technology parameter $B$ is fixed again simplifies the exposition and can be generalized. What is crucial for the results, though, is that $B$ fluctuates less than proportionately with productivity at the frontier.

Output produced in period $t$ becomes available for entrepreneurs' investment and consumption purposes in the next period. To obtain closedform solutions, capital fully depreciates within every period. Equivalently, $Y_{t}^{i}$ can be interpreted to include both output and undepreciated capital. In the calibration exercise, I use this interpretation and choose the capital share parameter $\alpha$ accordingly.

Each period, all agents have access to a capital market where they can borrow and lend at gross interest rate $R_{t}$. Borrowing can be against collateral only, however. Because labor income cannot be collateralized, workers are not permitted to borrow. Further, I show that in any steady state with constrained entrepreneurs, $R<1 / \beta$ holds, which implies that in any stochastic equilibrium near the steady state, workers do not save; hence, workers simply consume their wage income in every period.

Entrepreneurs, in turn, can pledge a fraction $\lambda<1$ of their output, where the "collateral share" parameter $\lambda$ plausibly depends both on technological features (e.g., what part of capital is alienable) and on the institutional framework and market environment (e.g., creditors' rights and availability of credit market instruments). Every entrepreneur's principal and interest on debt $D_{t}^{i}$ may not exceed the value of collateral. That is, the credit constraint takes the form $R_{t} D_{t}^{i} \leq \lambda Y_{t}^{i}$. Credit repayments occur at the beginning of the next period before realization of the next period's productivity.

For any realization of technology shocks $\left(A_{t}\right)_{t \geq 0}$, a competitive equilibrium is a list of consumption plans, production plans, and debt positions $\left(C_{t}^{i}, K_{t}^{i}, L_{t}^{i}, D_{t}^{i}\right)$ for every entrepreneur; consumption plans and debt positions for workers $\left(C_{t}^{W}, D_{t}^{W}\right)$; and factor prices for labor and capital $\left(w_{t}, R_{t}\right)$ such that in every period $t \geq 0^{4}$ :

(i) $C_{t}^{i}, K_{t}^{i}, L_{t}^{i}, D_{t}^{i}$ maximizes entrepreneur i's expected utility subject to budget and debt constraints; that is, it solves

\footnotetext{
4 In the initial period, $t=0$, all debt positions are assumed zero, and there is some given distribution of wealth across entrepreneurs.
} 


$$
\begin{aligned}
& \max E_{t} \sum_{s \geq t} \beta^{s-t} \ln C_{s}^{i} \quad \text { s.t. } \\
& C_{s}^{i}+K_{s}^{i}-D_{s}^{i}=A_{s-1}^{i}\left(K_{s-1}^{i}\right)^{\alpha}\left(L_{s-1}^{i}\right)^{1-\alpha} \\
& -W_{s-1} L_{s-1}^{i}-R_{s-1} D_{s-1}^{i}, s \geq t, \\
& R_{s} D_{s}^{i} \leq \lambda A_{s}^{i}\left(K_{s}^{i}\right)^{\alpha}\left(L_{s}^{i}\right)^{1-\alpha}, s \geq t .
\end{aligned}
$$

(ii) $C_{t}^{w}, D_{t}^{W}$ maximizes workers' expected utility subject to budget and zero debt constraints; that is; it solves

$$
\begin{aligned}
& \max E_{t} \sum_{s \geq t} \beta^{s-t} \ln C_{s}^{w} \quad \text { s.t. } \\
& C_{s}^{W}-D_{s}^{W}=w_{s}-R_{s-1} D_{s-1}^{W}, \quad s \geq t, \\
& D_{s}^{W} \leq 0, s \geq t .
\end{aligned}
$$

(iii) Markets for labor and capital clear:

$$
\begin{aligned}
& \int_{0}^{1} L_{t}^{i} d i=1 \\
& \int_{0}^{1} D_{t}^{i} d i+D_{t}^{W}=0 .
\end{aligned}
$$

The appendix characterizes the solutions to the agents' utility maximization problems. Particularly in the neighborhood of a steady-state equilibrium with binding constraints, workers do not save; hence, $D_{t}^{w}=0$ for all $t \geq 0$. Further, all entrepreneurs save a constant fraction $\beta$ of their wealth.

Before discussing an equilibrium with binding debt constraints, it is instructive to see how the economy acts when the collateral value $\lambda$ is large enough. In every period, then, all capital flows to productive entrepreneurs who also hire the total workforce. Because $\beta$ is the entrepreneurs' savings rate and because total entrepreneur wealth is share $\alpha$ of output, the aggregate capital stock evolves according to $K_{t+1}=\beta \alpha A_{t} K_{t}^{\alpha}$. The model's dynamics thus resemble those in the standard real business cycle model with logarithmic utility, Cobb-Douglas production, and full depreciation.

The following section characterizes equilibrium when productive entrepreneurs are credit constrained and unproductive entrepreneurs do not lend all their capital but also produce. Hence, production is inefficient and the steady-state out- put level is below the one in the first-best economy. A parameter restriction explained below will ensure that such an equilibrium exists.

\section{EQUILIBRIUM}

As is shown in the appendix, all entrepreneurs' capital investments are linear in their equity. Hence, aggregation over entrepreneurs with identical technologies is straightforward, and I write

$$
K_{t}^{A}=\int_{i: A_{t}^{i}=A_{t}} K_{t}^{i} d i \text { and } K_{t}^{B}=\int_{i: A_{t}^{i}=B} K_{t}^{i} d i
$$

to denote aggregate capital investment of productive and unproductive entrepreneurs. $L_{t}^{A}$ and $L_{t}^{B}$ are similarly defined, and the absence of a superindex indicates an aggregate across all entrepreneurs. Let $k_{t}^{s}=K_{t}^{s} / L_{t}^{s}, \mathrm{~s}=A, B$, denote capital intensities for the two types of entrepreneurs.

Because labor moves freely between employers, the real wage is

$$
w_{t}=A_{t}(1-\alpha)\left(k_{t}^{A}\right)^{\alpha}=B(1-\alpha)\left(k_{t}^{B}\right)^{\alpha},
$$

which implies that

$$
k_{t}^{B}=\varphi_{t} k_{t}^{A} \text { with } \varphi_{t} \equiv\left(A_{t} / B\right)^{1 / \alpha}>1 .
$$

Because labor is perfectly mobile and capital is not, unproductive entrepreneurs operate their technology with a higher capital intensity than productive entrepreneurs. The labor and capital markets are in equilibrium if

$$
L_{t}^{A}+L_{t}^{B}=1
$$

$$
L_{t}^{A} k_{t}^{A}+L_{t}^{B} k_{t}^{B}=K_{t} .
$$

Let $D_{t}$ denote total borrowing of productive entrepreneurs, which equals total lending of unproductive entrepreneurs because workers do not participate in the credit market. Because productive entrepreneurs own $\pi K_{t}$ units of the capital stock, their capital input is the sum of equity and debt:

$$
L_{t}^{A} k_{t}^{A}=\pi K_{t}+D_{t}
$$


Because the credit constraint binds on each productive entrepreneur, it also holds with equality in the aggregate:

$$
R_{t} D_{t}=\lambda A_{t}\left(k_{t}^{A}\right)^{\alpha} L_{t}^{A} .
$$

Unproductive entrepreneurs are indifferent between lending capital at gross return $R_{t}$ or producing themselves, which leads to the following arbitrage condition:

$$
R_{t}=\alpha B\left(k_{t}^{B}\right)^{\alpha-1}
$$

From equations (1), (5), and (6), it follows that borrowing is proportional to investment:

$$
D_{t}=\frac{\lambda A_{t}}{\alpha B}\left(k_{t}^{A}\right)^{\alpha}\left(k_{t}^{B}\right)^{1-\alpha} L_{t}^{A}=\frac{\lambda \varphi_{t}}{\alpha} k_{t}^{A} L_{t}^{A} ;
$$

and substitution into equation (4) yields

$$
D_{t}=\frac{\pi \lambda \varphi_{t}}{\alpha-\lambda \varphi_{t}} K_{t} .
$$

To ensure that unproductive entrepreneurs produce, their lending may not exceed their capital holdings; that is, $D_{t}$ must be strictly smaller than $(1-\pi) K_{t}$. Together with equation (8), this necessitates $\lambda \varphi_{t}<(1-\pi) \alpha$. Because $A_{t}$ fluctuates around $\bar{A}, \varphi_{t}$ fluctuates around $\bar{\varphi} \equiv(\bar{A} / B)^{1 / \alpha}$. To guarantee a production-inefficient equilibrium in the neighborhood of the steady state, it must therefore be assumed that

$$
\lambda \bar{\varphi}<(1-\pi) \alpha .
$$

The explanation of this condition is as follows. If the collateral share were too large, productive agents would borrow all resources from their unproductive counterparts and production would be efficient. The same would apply if either $\varphi$ or $\pi$ were too large: With a large productivity spread, production becomes less attractive than lending for unproductive agents, and a large share of borrowers raises credit above the funds supplied by lenders. Similarly, a too-low capital share would depress the interest rate, driving up the demand for credit above lenders' resources.
Now equations (1), (2), (3), (4), and (7) can be solved for the capital intensity of productive entrepreneurs as follows:

$$
k_{t}^{A}=C_{t} K_{t} \text { with } C_{t} \equiv \frac{\alpha-\lambda \varphi_{t}-\alpha \pi+\alpha \pi \varphi_{t}}{\varphi_{t}\left(\alpha-\lambda \varphi_{t}\right)}<1,
$$

where $C_{t}<1$ follows from condition (9) when $\varphi_{t}$ is close to its steady-state value, so that $C_{t}$ is close to its steady-state level, $\bar{C}<1$. This also implies that $k_{t}^{B}=\varphi_{t} C_{t} K_{t}>K_{t}$. Employment is allocated according to

$$
L_{t}^{A}=\frac{\alpha \pi}{C_{t}\left(\alpha-\lambda \varphi_{t}\right)} \text { and } L_{t}^{B}=\frac{\alpha\left(C_{t}-\pi\right)-C_{t} \lambda \varphi_{t}}{C_{t}\left(\alpha-\lambda \varphi_{t}\right)} \text {, }
$$

so aggregate output is

$$
Y_{t}=A_{t}\left(k_{t}^{A}\right)^{\alpha} L_{t}^{A}+B\left(k_{t}^{B}\right)^{\alpha} L_{t}^{B}=A_{t} C_{t}^{\alpha} K_{t}^{\alpha},
$$

with total factor productivity $A_{t} C_{t}^{\alpha}<A_{t}$. Because workers earn share 1- $\alpha$ of output and do not save and because all entrepreneurs save share $\beta$ of their wealth, the aggregate saving rate is $\alpha \beta$. Hence, the capital stock evolves according to

$$
K_{t+1}=\alpha \beta A_{t} C_{t}^{\alpha} K_{t}^{\alpha} .
$$

In the absence of technology shocks, the capital stock converges to its steady-state level:

$$
\bar{K}=\left(\alpha \beta \bar{A} \bar{C}^{\alpha}\right)^{1 /(1-\alpha)} .
$$

Note that the steady-state interest rate is $\bar{R}=$ $1 /(\bar{\varphi} \bar{C} \beta)<1 / \beta$; hence, workers indeed do not save when entrepreneurs are credit constrained.

The steady-state credit share in output is calculated as

$$
\frac{D}{Y}=\frac{\alpha \beta D}{K}=\frac{\alpha \beta \pi \lambda \bar{\varphi}}{\alpha-\lambda \bar{\varphi}} .
$$

An unproductive entrepreneur's capital grows at rate $\beta \bar{R}$, whereas a productive entrepreneur's capital grows at $\beta \tilde{R}>\beta \bar{R}$, where

$$
\tilde{R}=A\left(k^{A}\right)^{\alpha-1} \frac{\alpha(\alpha-\lambda)}{\alpha-\lambda \bar{\varphi}}
$$


is the return on equity. ${ }^{5}$ Therefore, the SD of a firm's growth rate in steady state is

$$
\sigma=\sqrt{\pi(1-\pi)} \beta(\tilde{R}-\bar{R})=\frac{\alpha(\bar{\varphi}-1)}{\alpha-\lambda \bar{\varphi}-\alpha \pi+\alpha \pi \bar{\varphi}} .
$$

The closed-form expressions (10) and (11) capture the central message of this paper. On the one hand, a rise in $\lambda$ describes the effect of credit market deepening in this model: When firms are able to pledge more of their assets as collateral, the share of credit in total output expands as shown in expression (10). In tandem with the credit expansion comes a higher firm volatility, as evidenced by equation (11). Relaxed credit limits spur leverage, widening the gap between firm growth rates, $\beta(\tilde{R}-\bar{R})$. On the other hand, a positive technology shock triggers a rise in credit and in firm volatility. The increase of $A$ (relative to $B$ ) raises $\varphi$, which unambiguously increases $D / Y$ and $\sigma$ (which is again an implication of inequality (9)). Intuitively, a positive productivity shock boosts the value of collateral and thus the volume of credit. Notably, credit rises more than one-for-one with output, so the share of credit in output also increases. Additionally, the positive technology shock stimulates leverage, which enlarges the spread between firm growth rates, increasing firm volatility.

\section{QUANTITATIVE ANALYSIS}

This section explores the quantitative properties of the qualitative results obtained in the previous section: How well does this model explain the observed dynamics of output, business credit, and firm volatility? To calibrate the steady state, I first choose the following five parameters: the capital share, $\alpha$; the discount factor, $\beta$; the collateral share, $\lambda$; the mean spread between technologies, $\bar{\varphi}$; and the share of productive entrepreneurs, $\pi$. The technology level $\bar{A}$ (and thus $B$ ) merely shifts the level of aggregate output and capital but has no impact on the capital-to-output ratio

\footnotetext{
5 An entrepreneur with equity $E$ borrows $D=\lambda \varphi E /(\alpha-\lambda \varphi)$ and invests $K^{A}=\alpha E /(\alpha-\lambda \varphi)$ to earn profit $\pi=A\left(K^{A}\right)^{\alpha-1} K^{A}-R D$ $w K^{A} / K^{A}=\alpha A\left(k^{A}\right)^{\alpha-1} K^{A}-\lambda A\left(k^{A}\right)^{\alpha-1} K^{A}=\tilde{R} E$.
}

or on any other relevant economic variables. Therefore, I normalize $\bar{A}=1$.

Because there is no depreciation in this model, I adjust the capital share to include the value of the undepreciated capital stock. In the following, the term "wealth" refers to GDP plus undepreciated capital, $Y=\mathrm{GDP}+(1-\delta) K$. With an annual capital-to-GDP ratio of $K / G D P=2.7$ and a 5 percent depreciation rate, the wealth-to-GDP ratio is 3.57. With capital income in GDP at one-third, it follows that the capital share in wealth is $\alpha=$ $[0.33+(0.95 \cdot 2.7)] / 3.57 \approx 0.81$. Further, in steady state, $\alpha \beta=K / Y=2.7 / 3.57$, which yields $\beta=0.938$. I choose the collateral share, $\lambda$, to match a share of business credit in GDP of around 0.55, the average over the period 1955-2000. As equation (10) gives the credit-to-wealth ratio, the righthand side of this equation must be equalized to $0.55 / 3.57$. Given the above choices for $\alpha$ and $\beta$, and for any choice of $\bar{\varphi}$ and $\pi$, $\lambda$ is chosen to satisfy this equation. The remaining parameters $\pi$ and $\bar{\varphi}$ are chosen to match the following two targets: a 3 percent real interest rate $(\bar{R}=1.03)$ and a value of firm volatility (measured by the SD of firm growth) of around 0.14 , the average of median firm volatility during 1955-2000. This yields $\bar{\varphi}=1.13$ and $\pi=0.08$, which in turn implies that $\lambda=0.51$. At these parameter values, assumption (9) is satisfied by a wide enough margin. On the other hand, if $\lambda$ would exceed $\alpha(1-\pi) / \bar{\varphi} \approx 0.66$, assumption (9) would be violated, in which case all capital would be used at the technology frontier. Although productive entrepreneurs may still be credit constrained, ${ }^{6}$ the model behaves like a standard real business cycle model and the value of $\lambda$ has no effect on aggregate output.

In the stochastic model of this section, I do not compute firm volatility defined over an infinite time horizon-which, in steady state, gives rise to equation (11) for every firm. Instead, I follow the procedure of Comin and Philippon (2005) to calculate rolling SDs of firm growth rates over 10-year time windows. Specifically, at each point

\footnotetext{
6 Precisely, when $\lambda<\alpha(1-\pi) \approx 0.75$, the steady-state interest rate stays below the marginal product of capital of productive entrepreneurs. Although the economy would be production efficient, it is consumption inefficient because idiosyncratic volatility still matters. First-best allocations are attained only when $\lambda>\alpha(1-\pi)$.
} 
Figure 3

\section{Response to a 5 Percent Permanent Increase in the Collateral Share $\lambda$ in Period $t=5$}
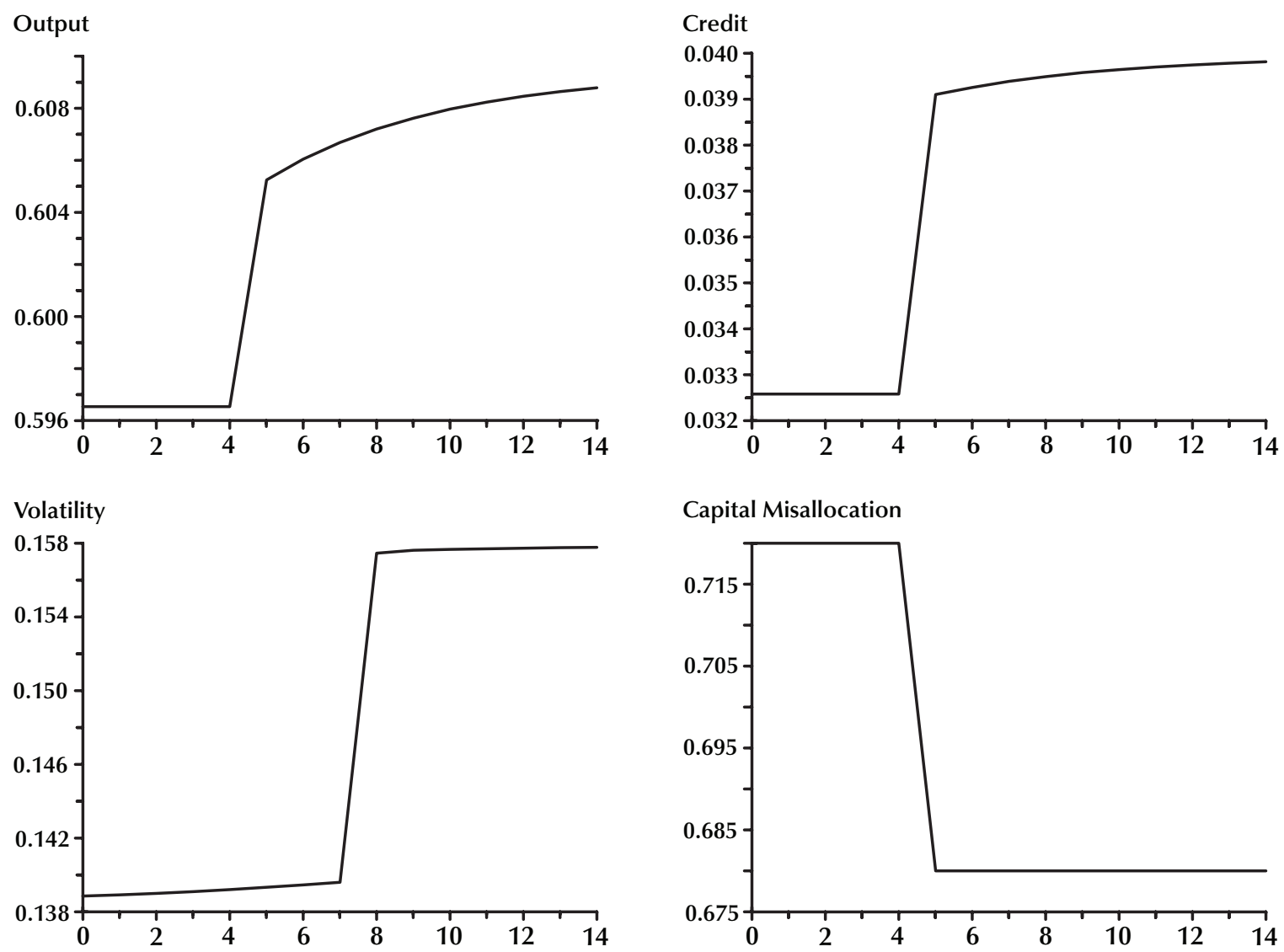

Capital Misallocation

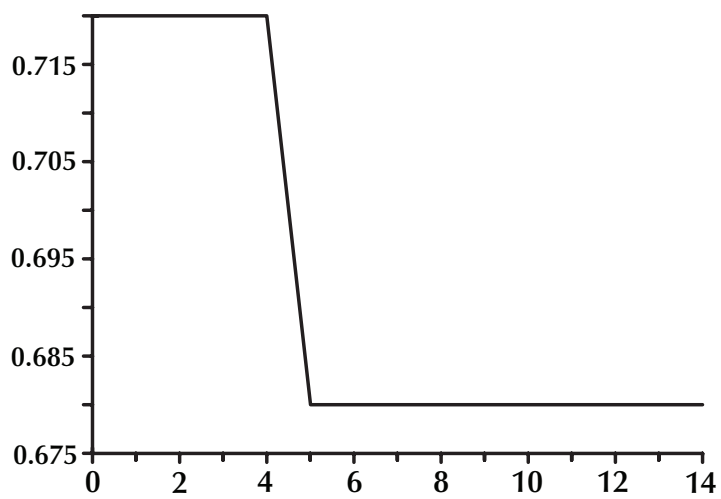

in time $t$, I bootstrap the distribution of these SDs from 10,000 firms drawing their growth rates from $\left(\beta R_{t+\tau}, \beta \tilde{R}_{t+\tau}\right)_{\tau=-4}^{5}$. Then I use the median of this distribution as the volatility measure.

Figure 3 shows the model's response to a permanent increase in the collateral share $\lambda$ by about 5 percent. Output increases on impact by 1.3 percent, converging to the new steady state, which is more than 2 percent higher. Credit increases by about 23 percent, and volatility increases by 15 percent. The response of volatility is sluggish; also, the response begins four periods before the shock because volatility is constructed using rolling windows that are four periods backward looking and five periods forward looking. The largest adjustment of volatility occurs three periods after the shock. The lower-right graph shows the "capital misallocation," defined as the share of capital used by unproductive entrepreneurs. Note that only 8 percent of entrepreneurs have access to the technology frontier, but they still use 28 percent of capital when $\lambda=0.51$. As $\lambda$ increases to $0.535,32$ percent of capital is used at the technology frontier.

Whereas this experiment shows the effect of a permanent rise in collateral value, it also is illuminating to investigate the impact of a temporary decline in collateral value as a result of a severe financial crisis. To this end, suppose that the collateral share drops by 20 percent for a period of three years before it returns to its original value. I find that the impact of such a shock is a decline 


\section{Figure 4}

\section{Response to a 1 Percent Permanent Increase in Productivity $A$ in Period $t=5$}
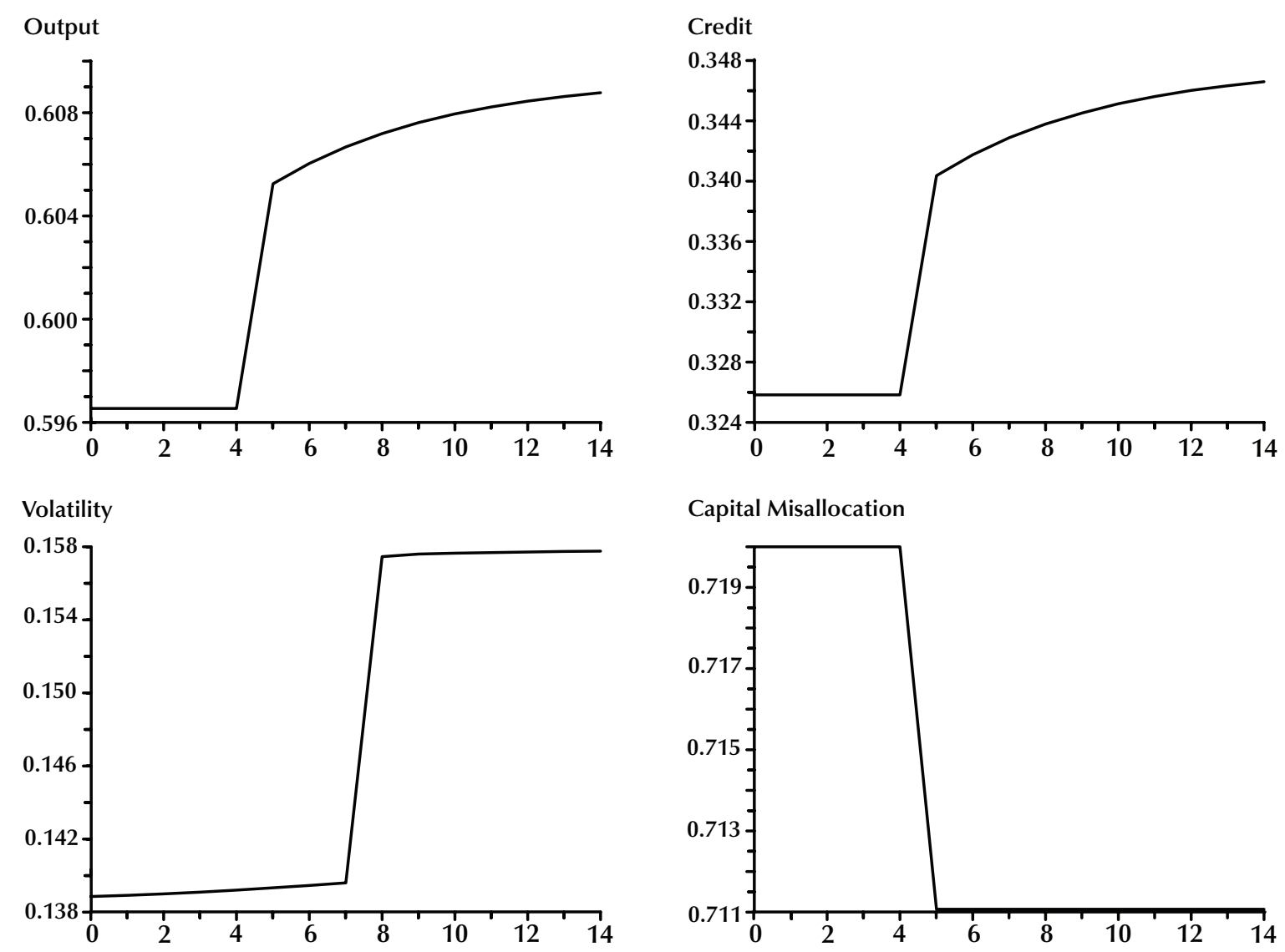

Capital Misallocation

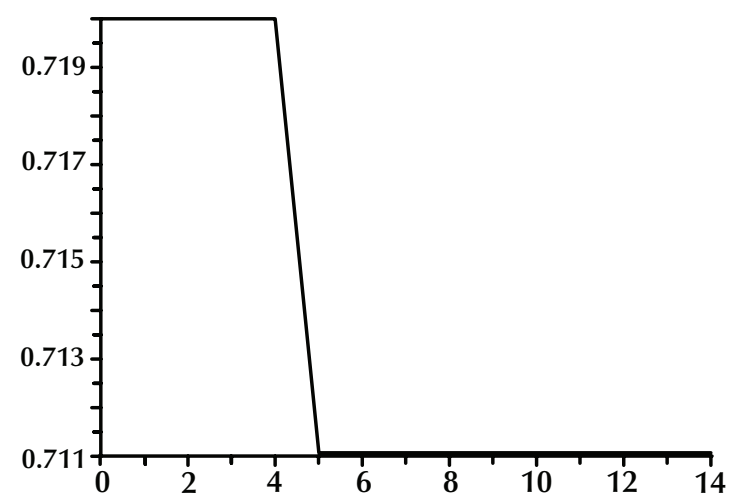

of GDP by 3 to 3.5 percent in the three years of the crisis, the largest occurring in the third year. Because the model has little amplification, output returns to 0.5 percent below its steady-state level in the first year after the crisis. During the three crisis years, credit collapses dramatically: It falls by more than 40 percent, which implies that only 20 percent of capital is used at the frontier technology. Note again that these macroeconomic effects of a decline of $\lambda$ are due to the misallocation of capital; they would disappear if $\lambda$ exceeded the threshold level implied by assumption (9). Public policy may attempt to prevent the adverse effects of the credit collapse to some extent, either by restoring collateral value or by the injection of liquidity—for example, by providing unsecured credit lines. Without analyzing such policies formally, it is clear that they must be of a large scale, given the substantial decline of the credit market.

Figure 4 shows the impulse response to a permanent increase of productivity at the technology frontier by 1 percent. As the value of pledgeable assets rises, credit expands by 6 percent, and the higher leverage leads to an increase of firm volatility by about 15 percent. Output increases by 2 percent, which comes about through two effects: The first is higher productivity at the technology frontier; the second is that capital is now more efficiently allocated as capital misallocation falls from 0.72 to 0.711 .

To explore the stochastic model with autocorrelated shocks, 


\section{Table 2}

\section{Simulation Results with Stochastic Productivity for 10,000 Model Periods}

\begin{tabular}{lccc} 
& Output & Credit & Volatility \\
\hline Standard deviation & 0.022 & 0.061 & 0.130 \\
Annual autocorrelation & 0.534 & 0.542 & 0.643 \\
Correlation matrix & & & \\
$\quad$ Output & 1 & 0.980 & 0.177 \\
Credit & - & 1 & 0.183 \\
Volatility & - & - & 1
\end{tabular}

NOTE: All variables are reported in logs as deviations from an $\mathrm{H}-\mathrm{P}$ trend with smoothing parameter 100.

$$
\ln A_{t}=\rho \ln A_{t-1}+\sigma \varepsilon_{t}, \quad \varepsilon_{t} \sim \mathcal{N}(0,1),
$$

I choose the two parameters $\rho$ and $\sigma$ to target the $\mathrm{SD}$ and autocorrelation of the cyclical component of the model-generated GDP time series. As explained previously, GDP in period $t$ is the difference between $Y_{t}$ and the undepreciated capital stock, which is $0.95 K_{t}=0.95 \alpha \beta Y_{t-1}$. All time series again are detrended with an H-P filter with smoothing parameter 100, and the cyclical components are the log deviations from trend. The result of this exercise is that $\rho=0.95$ and $\sigma=0.014$ match the first two moments in Table 1 reasonably well. These and all other model-generated moments from a simulation with $10^{5}$ periods are listed in Table 2. Relative to the data, the amplification of credit is matched reasonably well, whereas the SD of firm volatility is more than twice as large as in the data. Although all contemporaneous correlations have the right sign, the one between output and credit is larger than in the data, whereas the cross-correlations with volatility are too low.

Volatility is strongly amplified because productivity of the inferior technology stays constant. If $B$ were to fluctuate with $A$ according to $B_{t} / \bar{B}=$ $\left(A_{t} / \bar{A}\right)^{\gamma}$, the SD of firm volatility would halve in value for $\gamma=0.5$, and it would (counterfactually) become smaller than the SD of output for $\gamma=1$. Proper calibration of the stochastic dynamics of both $A_{t}$ and $B_{t}$ would require matching the time- series properties of the mean and the SD of the cross-sectional productivity distribution, which is beyond the scope of this paper.

\section{CONCLUSION}

This paper has developed a tractable real business cycle model with idiosyncratic productivity shocks and collateral-based credit constraints. Important features of the model are that output is below the efficient level because not all capital is used at the technological frontier and that firm growth rates are volatile. The model allows derivation of closed-form expressions for the dynamics of output and capital, for the volume of credit, and the SD of firm growth rates. It accounts qualitatively for the observed simultaneous long-term increase of the credit-to-output ratio and of firm volatility. Quantitatively, the model is able to generate the correct comovement among output, credit, and firm volatility, although firm volatility is too strongly amplified.

\section{REFERENCES}

Blanchard, Olivier J. and Simon, John A. "The Long and Large Decline in U.S. Output Volatility." Brookings Papers on Economic Activity, March 2001, 2001(1), pp. 135-64.

Campbell, John Y.; Lettau, Martin; Malkiel, Burton G. and $\mathrm{Xu}$, Yexiao. "Have Individual Stocks Become More Volatile? An Empirical Exploration of Idiosyncratic Risk." Journal of Finance, February 2001, 56(1), pp. 1-43.

Comin, Diego and Mulani, Sunil. "Diverging Trends in Macro and Micro Volatility: Facts." NBER Working Paper 10922, National Bureau of Economic Research, November 2004; www.nber.org/papers/ w10922.

Comin, Diego and Philippon, Thomas. "The Rise in Firm-Level Volatility: Causes and Consequences." NBER Working Paper 11388. National Bureau of Economic Research, May 2005; www.nber.org/ papers/w11388. 
Davis, Steven, J.; Haltiwanger, John; Jarmin, Ron and Miranda, Javier. "Volatility and Dispersion in Business Growth Rates: Publicly Traded versus Privately Held Firms.” NBER Working Paper 12354, National Bureau of Economic Research; June 2006; www.nber.org/papers/w12354.

Board of Governors of the Federal Reserve System. Federal Reserve Statistical Release, Z.1. Flow of Funds Accounts of the United States: Flows and Outstandings Third Quarter 2008. Credit Market Debt Outstanding (December 11, 2008).

Washington, DC: Board of Governors, 2008; www.census.gov/compendia/statab/tables/ 09s1130.xls.

Hopenhayn, Hugo A. and Vereshchagina, Galina. “Risk Taking by Entrepreneurs.” Rochester Center for Economic Research Working Paper 500, University of Rochester, April 2003; http://rcer.econ.rochester.edu/RCERPAPERS/ rcer_500.pdf.
Kiyotaki, Nobuhiro. "Credit and Business Cycles." Japanese Economic Review, March 1998, 49(1), pp. 18-35.

Kiyotaki, Nobuhiro and Moore, John. "Liquidity, Business Cycles, and Monetary Policy.” Working Paper, Princeton University, April 2008; www.princeton.edu/ kiyotaki/papers/ChiKM6-1.pdf.

Meh, Cesaire A. and Quadrini, Vincenzo. "Endogenous Market Incompleteness with Investment Risks.” Journal of Economic Dynamics and Control, November 2006, 30(11), pp. 2143-65.

Stock, James H. and Watson, Mark W. "Has the Business Cycle Changed and Why?” NBER Working Paper 9127, National Bureau of Economic Research, August 2002; www.nber.org/papers/w9127.

\section{APPENDIX}

This appendix characterizes the solutions to the workers' and entrepreneurs' utility maximization problems. Consider entrepreneurs first, and suppose that productive entrepreneurs are debt constrained, which requires that

$$
R_{t}<\alpha A_{t}^{1 / \alpha}\left[(1-\alpha) / w_{t}\right]^{(1-\alpha) / \alpha}
$$

for all $t \geq 0$. All entrepreneurs hire labor to equalize marginal product to the wage; hence,

$$
L_{t}^{i}=K_{t}^{i}\left[A_{t}^{i}(1-\alpha) / w_{t}\right]^{1 / \alpha} .
$$

Consider first productive entrepreneurs $\left(A_{t}^{i}=A_{t}\right)$. They borrow up to their debt limit because the marginal product of capital exceeds the interest rate because of equation (A1); hence,

$$
D_{t}^{i}=\frac{\lambda A_{t} K_{t}^{i}}{R_{t}}\left[A_{t}(1-\alpha) / w_{t}\right]^{(1-\alpha) / \alpha} .
$$

Let $S_{t}^{i}=K_{t}^{i}-D_{t}^{i}$ denote equity (savings) of the entrepreneur. Wealth at the end of period $t$ is proportional to the borrower's capital investment and also proportional to equity: 


$$
\begin{aligned}
& A_{t}\left(K_{t}^{i}\right)^{\alpha}\left(L_{t}^{i}\right)^{1-\alpha}-w_{t} L_{t}^{i}-R_{t} D_{t}^{i} \\
& =(\alpha-\lambda) A_{t}\left[A_{t}(1-\alpha) / w_{t}\right]^{(1-\alpha) / \alpha} K_{t}^{i} \\
& =\frac{R_{t}(\alpha-\lambda)}{R_{t} A_{t}^{-1 / \alpha}\left[w_{t} /(1-\alpha)\right]^{(1-\alpha) / \alpha}-\lambda} S_{t}^{i} \\
& =\tilde{R}_{t} S_{t}^{i} .
\end{aligned}
$$

Here $\tilde{R}_{t}$ is the return on equity for an entrepreneur who is productive in period $t$. Consequently, the budget constraint in period $t+1$ reads as $C_{t+1}^{i}+S_{t+1}^{i}=\tilde{R}_{t} S_{t}^{i}$. Consider next an unproductive entrepreneur in period $t$; that is, $A_{t}^{i}=B$. There are two possibilities. First, either the interest rate exceeds the marginal product of capital of these entrepreneurs-in which case they do not produce and their return on savings is simply $R_{t}$-or, as is assumed in the main text, the interest rate equals their marginal product of capital, ${ }^{7}$ which requires that

$$
R_{t}=\alpha B^{1 / \alpha}\left[(1-\alpha) / w_{t}\right]^{(1-\alpha) / \alpha} .
$$

Again, $S_{t}^{i}=K_{t}^{i}-D_{t}^{i}$ is savings and $-D_{t}^{i}>0$ are financial assets of unproductive entrepreneur $i$. Wealth at the end of period $t$ is again proportional to savings:

$$
\begin{aligned}
& B\left(K_{t}^{i}\right)^{\alpha}\left(L_{t}^{i}\right)^{1-\alpha}-w_{t} L_{t}^{i}-R_{t} D_{t}^{i}=\alpha B\left(K_{t}^{i}\right)^{\alpha}\left(L_{t}^{i}\right)^{1-\alpha}-R_{t} D_{t}^{i} \\
& =R_{t}\left(K_{t}^{i}-D_{t}^{i}\right)=R_{t} S_{t}^{i} .
\end{aligned}
$$

Therefore, any entrepreneur's budget constraint in period $t+1$ reads as $C_{t+1}^{i}+S_{t+1}^{i}=R_{t}^{i} S_{t}^{i}$, where $R_{t}^{i}=R_{t}$ if the entrepreneur is unproductive in period $t$ and $R_{t}^{i}=\tilde{R}_{t}$ if the entrepreneur is productive in $t$. The Euler equation for entrepreneur i's utility maximization problem is then

$$
\frac{1}{C_{t}^{i}}=\beta R_{t}^{i} E_{t} \frac{1}{C_{t+1}^{i}}
$$

Clearly, constant consumption/saving shares $C_{t+1}^{i}=(1-\beta) R_{t}^{i} S_{t}^{i}$ and $S_{t+1}^{i}=\beta R_{t}^{i} S_{t}^{i}$ are the only solution to this equation that satisfy the transversality condition.

For workers, the Euler equations for their problem specified in (ii) of the equilibrium definition is

$$
\frac{1}{C_{t}^{W}} \geq \beta R_{t} E_{t} \frac{1}{C_{t+1}^{W}}, \quad D_{t}^{W} \leq 0
$$

with complementary slackness. In the main text, it is shown that $R_{t} \beta<1$ holds in the neighborhood of the steady state. Further, in the neighborhood of the steady state (i.e., small-enough productivity shocks), $w_{t} \approx \bar{W}$ and $E_{t}\left(1 / w_{t+1}\right) \approx 1 / \bar{W}$ hold, where $\bar{W}$ is the steady-state wage level. Therefore, it follows from the complementary slackness condition that $D_{t}^{W}=0$ and $C_{t}^{W}=w_{t}$ for all $t \geq 0$.

7 The third case- - that the interest rate is below the marginal product of capital of all entrepreneurs-is incompatible with equilibrium; then all entrepreneurs would be lenders, whereas workers do not save (as shown below). Hence, the capital market cannot be in equilibrium. 